\title{
Association of Leptin Gene Polymorphisms with Rheumatoid Arthritis in a Chinese Population
}

\author{
Sha-Sha Tao $\mathbb{D},{ }^{1,2}$ Yi-Lin Dan $\mathbb{D}^{1,2}$ Guo-Cui Wu $\mathbb{D}^{3},{ }^{3}$ Qin Zhang $\mathbb{D},{ }^{1,2}$ Tian-Ping Zhang $\mathbb{D}^{1,2}$ \\ Yin-Guang Fan $D^{1,2}$ and Hai-Feng Pan iD ${ }^{1,2}$ \\ ${ }^{1}$ Department of Epidemiology and Biostatistics, School of Public Health, Anhui Medical University, 81 Meishan Road, Hefei, \\ Anhui, China \\ ${ }^{2}$ Anhui Provincial Laboratory of Inflammatory and Immune Diseases, 81 Meishan Road, Hefei, Anhui, China \\ ${ }^{3}$ School of Nursing, Anhui Medical University, 15 Feicui Road, Hefei, Anhui, China
}

Correspondence should be addressed to Hai-Feng Pan; panhaifeng@ahmu.edu.cn

Received 13 April 2020; Revised 19 September 2020; Accepted 1 October 2020; Published 6 October 2020

Academic Editor: Cristiano Caruso

Copyright (C) 2020 Sha-Sha Tao et al. This is an open access article distributed under the Creative Commons Attribution License, which permits unrestricted use, distribution, and reproduction in any medium, provided the original work is properly cited.

Background. Recently, increasing studies have revealed that leptin is involved in the development of rheumatoid arthritis (RA). This study is aimed at exploring the association of leptin gene single nucleotide polymorphisms (SNPs) with susceptibility to RA in a Chinese population. Methods. We recruited 600 RA patients and 600 healthy controls from a Chinese population and analyzed their three leptin SNPs (rs10244329, rs2071045, and rs2167270) using the improved Multiplex Ligase Detection Reaction (iMLDR) assays. The associations of these SNPs with clinical manifestations of RA were also analyzed. Enzyme-linked immunosorbent assay (ELISA) was performed for plasma leptin determination. Results. No significant difference in either allele or genotype frequencies of these three SNPs between RA patients and healthy controls was observed (all $P>0.05$ ). Association between the genotype effects of dominant, recessive models was also not found (all $P>0.05$ ). No significant difference in plasma leptin levels was detected between RA patients and controls $(P>0.05)$. Conclusion. Leptin gene (rs10244329, rs2071045, and rs2167270) polymorphisms are not associated with RA genetic susceptibility and its clinical features in the Chinese population.

\section{Introduction}

Rheumatoid arthritis (RA) is one type of systemic autoimmune diseases, featured by progressive destruction of the cartilage, bone, and joint eventually, which ultimately leads to a chronic, destructive inflammatory arthritis [1]. The disease destructs synovial small and large joints, for instance, fingers, elbows, shoulders, ankles, and knees [2]. RA patients usually have severe disability or early death resulting from thickening and hyperplasia of the synovial line and chronic inflammatory [3]. With a global prevalence of $1 \%$, RA is still a serious public health problem that harms health and increases financial burden, especially in the developing countries in Asia [4-6]. Although the precise aetiology of RA remains unknown, increasing studies have pointed out that leptin takes parts in its pathogenesis [7-11].
Leptin, the precursor and most characteristic member of the adipokine family, is a $16 \mathrm{kD}$ nonglycosylated cytokinelike hormone encoded by the obese $(o b)$ gene, the murine homolog of the human leptin gene [12]. In recent years, numerous studies have revealed that leptin has been implicated in inflammation and autoimmunity [13-19]. Emerging evidence has indicated that leptin is involved in RA [7, 9, 20-26]. Some studies have detected increased serum levels of leptin in RA patients [27-37], while others have suggested reduced levels [38-41].

Moreover, the function of the leptin gene in autoimmune diseases has received much attention in recent years [42-46]. It have been revealed that leptin plays a crucial role in the susceptibility to multiple sclerosis (MS) [42, 43] and systemic lupus erythematosus (SLE) [44]. It also has been reported that leptin-deficient mice had decreased levels of TNF- $\alpha$ 
and IL- $1 \beta$, a less severe arthritis induced by antigen and defective cell-mediated immunity [47]. Nevertheless, some other studies claimed that the leptin polymorphism was not associated with the risk of RA $[48,49]$. However, the association between leptin polymorphisms and RA in the Chinese population has not been studied as yet.

Therefore, in this case-control study, we detected the association of leptin gene polymorphisms (rs10244329, rs2071045, and rs2167270) with the susceptibility to RA in a Chinese population.

\section{Materials and Methods}

2.1. Patients and Control Subjects. In this study, $600 \mathrm{RA}$ patients were recruited from the Department of Rheumatology and Immunology at the First Affiliated Hospital of Anhui Medical University and the First Affiliated Hospital of University of Science and Technology of China. All the RA patients met the criteria of the American College of Rheumatology (ACR)/European League Against Rheumatism collaborative initiative (EULAR) revised in 2010 [50]. And 600 healthy controls were enlisted from the Health Examination Centre of the First Affiliated Hospital of Anhui Medical University and the Second Affiliated Hospital of Anhui Medical University. All the healthy controls should have no history of any signs or symptoms of autoimmune diseases. Patients' demographic data and clinical manifestations, including anticyclic citrullinated peptide (anti-CCP) and rheumatoid factor (RF), were collected through reviewing medical records or by questionnaire. This study was approved by the Medical Ethics Committee of Anhui Medical University, and informed consent was provided by all participants.

2.2. DNA Extraction and SNP Genotyping. Peripheral blood was extracted from study subjects, and the genomic DNA was obtained from the peripheral blood lymphocytes according to the standard procedures with the Wizard Genomic DNA Purification Kit (Promega, Madison, Wisconsin, USA). Quantification and concentration of DNA was determined applying agarose gel electrophoresis and using a NanoDrop 2000 Spectrophotometer (Thermo Fisher Scientific, USA). Qualified sample requirements are as follows: concentration greater than $50 \mathrm{ng} / \mu \mathrm{l}$, total amount greater than $600 \mathrm{ng}$, and no obvious degradation.

The genotyping of three SNPs was analyzed by applying the improved Multiplex Ligase Detection Reaction (iMLDR) assay technology and an ABI3730XL automated sequencer (Applied Biosystems, USA). Only patients with 100\% genotype success rate for all three SNPs can be included in this study. Therefore, finally, we analyzed the three leptin SNPs (rs10244329, rs2071045, and rs2167270) in 595 RA patients and 599 normal controls.

2.3. Plasma Leptin Detection. In the determination of plasma leptin levels, 103 RA patients and 95 health controls were recruited. We collected $5 \mathrm{ml}$ peripheral venous blood of all subjects and extracted plasma. Enzyme-linked immunosorbent assay (ELISA) kits (4Abiotech, China) were used for plasma leptin determination.
TABle 1: The demographic characteristics and laboratory parameters of RA patients.

\begin{tabular}{lcc}
\hline Characteristics & $\begin{array}{c}\text { RA patients } \\
(N=595)\end{array}$ & $\begin{array}{c}\text { Healthy controls } \\
(N=599)\end{array}$ \\
\hline Age (years) mean \pm SD & $52.35 \pm 12.75$ & $51.69 \pm 6.83$ \\
Sex (female/male) & $494 / 101$ & $499 / 100$ \\
Anti-CCP positive no. (\%) & $487(86.81)$ & - \\
RF positive no. (\%) & $479(83.16)$ & - \\
\hline
\end{tabular}

Anti-CCP: anticyclic citrullinated peptide; $N$ : number; RA: rheumatoid arthritis; RF: rheumatoid factor.

2.4. Statistical Analysis. The chi-square $\left(\chi^{2}\right)$ or Fisher's exact test was applied to analyze whether the genotype and allele frequencies of all SNPs between RA patients and controls are different. Haplotype analysis was conducted by applying an online SHEsis software (http://analysis.bio-x.cn/ myAnalysis.php) [51]. Odds ratios (ORs) and 95\% confidence intervals (95\% CIs) were calculated. The HardyWeinberg equilibrium (HWE) was evaluated applying the chi-square $\left(\chi^{2}\right)$ test. A two-tailed $P$ value less than 0.05 was regarded as statistically significant. All above-mentioned statistical analyses were performed by the SPSS 10.01 (SPSS Inc., IL, USA).

\section{Results}

3.1. Basic Characters of Study Subjects for Genotyping. The RA patients were composed of 101 males and 494 females with an average age of52.35 \pm 12.75 years, while the healthy controls were composed of 100 males and 499 females with an average age of $51.69 \pm 6.83$ years. No significant differences were found in age and gender between the RA patients and health controls. According to the data of anti-CCP and RF status, the RA patients can be divided into different serotypes. Finally, 487 (86.81\%) patients were diagnosed as anti-CCP positive and $479(83.16 \%)$ patients were diagnosed as RF positive (Table 1). The genotype distributions of rs10244329, rs2071045, and rs2167270 in healthy controls were in accordance with the Hardy-Weinberg equilibrium (all $P>0.05$ ).

3.2. The Associations between Leptin Gene rs10244329, rs2071045, and rs2167270 Polymorphisms and RA Susceptibility. The genotype and allele frequencies of rs10244329, rs2071045, and rs2167270 in RA patients and healthy controls are expressed in Table 2. No significant difference in genotype distributions of three SNP polymorphisms was discovered in RA patients compared to healthy controls (all $P>0.05$ ). Unfortunately, the three SNP polymorphisms also did not achieve a significant difference in allele frequencies between RA patients and controls (all $P>$ 0.05). Moreover, there was no significant difference in the frequency of three SNP polymorphisms under two main genetic models (dominant and recessive models) between RA patients and controls (all $P>0.05$ ).

3.3. The Associations of Leptin Gene rs10244329, rs2071045, and rs2167270 Polymorphisms with Risk of Different Serotypes of $R A$. A case-only study was conducted to analyze 
TABLE 2: Genotype and allele frequencies of leptin gene in RA patients and controls.

\begin{tabular}{|c|c|c|c|c|c|}
\hline SNP & Analyzed model & RA patients $[n(\%)]$ & Control $[n(\%)]$ & $P$ value & OR (95\% CI) \\
\hline & Genotype & & & & \\
\hline & $\mathrm{AA}$ & $332(55.80)$ & $341(56.93)$ & 0.255 & $0.765(0.481-1.215)$ \\
\hline & AT & $228(38.32)$ & $211(35.23)$ & 0.689 & $0.689(0.428-1.109)$ \\
\hline & $\mathrm{TT}$ & $35(5.88)$ & $47(7.85)$ & Reference & \\
\hline & Allele & & & & \\
\hline & A & $892(74.96)$ & $893(74.54)$ & 0.815 & $0.978(0.813-1.177)$ \\
\hline \multirow[t]{13}{*}{ rs10244329 } & $\mathrm{T}$ & $298(25.04)$ & $305(25.46)$ & Reference & \\
\hline & Dominant model & & & & \\
\hline & AA & $332(55.80)$ & $341(56.93)$ & 0.694 & $1.047(0.833-1.316)$ \\
\hline & $\mathrm{TT}+\mathrm{AT}$ & $263(44.20)$ & $258(43.07)$ & Reference & \\
\hline & Recessive model & & & & \\
\hline & $\mathrm{AA}+\mathrm{AT}$ & $560(94.12)$ & $552(92.15)$ & 0.180 & $0.734(0.467-1.155)$ \\
\hline & $\mathrm{TT}$ & $35(5.88)$ & $47(7.85)$ & Reference & \\
\hline & Genotype & & & & \\
\hline & $\mathrm{CC}$ & $194(32.61)$ & $203(33.89)$ & 0.992 & $1.002(0.723-1.387)$ \\
\hline & $\mathrm{CT}$ & $289(48.57)$ & $279(46.58)$ & 0.614 & $0.924(0.680-1.256)$ \\
\hline & $\mathrm{TT}$ & $112(18.82)$ & $117(19.53)$ & Reference & \\
\hline & Allele & & & & \\
\hline & $\mathrm{C}$ & $677(56.89)$ & $685(57.18)$ & 0.887 & $1.012(0.860-1.190)$ \\
\hline \multirow[t]{13}{*}{ rs2071045 } & $\mathrm{T}$ & $513(43.11)$ & $513(42.82)$ & Reference & \\
\hline & Dominant model & & & & \\
\hline & $\mathrm{CC}$ & $194(32.61)$ & $203(33.89)$ & 0.638 & $1.060(0.833-1.348)$ \\
\hline & $\mathrm{TT}+\mathrm{CT}$ & $401(67.39)$ & $396(66.11)$ & Reference & \\
\hline & Recessive model & & & & \\
\hline & $\mathrm{CC}+\mathrm{CT}$ & $483(81.18)$ & $482(80.47)$ & 0.756 & $1.047(0.785-1.396)$ \\
\hline & $\mathrm{TT}$ & $112(18.82)$ & $117(19.53)$ & Reference & \\
\hline & Genotype & & & & \\
\hline & GG & $366(61.51)$ & $374(62.44)$ & 0.285 & $0.743(0.431-1.282)$ \\
\hline & GA & $205(34.45)$ & $192(32.05)$ & 0.178 & $0.681(0.389-1.194)$ \\
\hline & AA & $24(4.03)$ & $33(5.51)$ & Reference & \\
\hline & Allele & & & & \\
\hline & G & $937(78.74)$ & $940(78.46)$ & 0.870 & $0.984(0.809-1.196)$ \\
\hline \multirow[t]{7}{*}{ rs2167270 } & A & $253(21.26)$ & $258(21.54)$ & Reference & \\
\hline & Dominant model & & & & \\
\hline & GG & $366(61.51)$ & $374(62.44)$ & 0.742 & $1.040(0.823-1.314)$ \\
\hline & $\mathrm{AA}+\mathrm{GA}$ & $229(38.49)$ & $225(37.56)$ & Reference & \\
\hline & Recessive model & & & & \\
\hline & $\mathrm{GG}+\mathrm{GA}$ & $571(96.67)$ & $566(94.49)$ & 0.232 & $0.721(0.412-1.235)$ \\
\hline & AA & $24(4.03)$ & $33(5.51)$ & Reference & \\
\hline
\end{tabular}

CI: confidence interval; OR: odds ratios; $n$ : number; SNP: single nucleotide polymorphism.

the relationship of leptin gene rs10244329, rs2071045, and rs2167270 polymorphisms and genetic susceptibility to different serotypes of RA patients. However, no significant genetic heterogeneity was observed between anti-CCPpositive and anti-CCP-negative RA patients and also between RF-positive and RF-negative RA patients (Table 3).

3.4. Haplotype Analysis. Eight haplotypes (AAC, AAT, ATC, ATT, GAC, GAT, GTC, and GTT) for leptin genes were iden- tified by applying the SHEsis software (Table 4). Unfortunately, no significant differences in haplotype distributions of these three SNP polymorphisms between RA patients and healthy controls were observed (all $P>0.05$ ).

3.5. Plasma Leptin Detection. We recruited 103 RA patients and 95 healthy controls for plasma leptin detection, without difference in gender and age. As per the results, no significant difference was found in plasma leptin concentrations 
TABLE 3: Associations of leptin gene polymorphisms with risk of different serotypes of RA.

\begin{tabular}{|c|c|c|c|c|c|c|c|c|c|}
\hline \multirow{2}{*}{$\begin{array}{l}\text { SNP } \\
\text { Allele }(\mathrm{M} / \mathrm{m})\end{array}$} & \multirow{2}{*}{ Clinical features } & \multirow[b]{2}{*}{ Group } & \multicolumn{3}{|c|}{ Genotype $[n(\%)]$} & \multirow{2}{*}{$P$ value } & \multicolumn{2}{|c|}{ Allele [n(\%)] } & \multirow{2}{*}{$P$ value } \\
\hline & & & MM & $\mathrm{Mm}$ & $\mathrm{mm}$ & & M & $\mathrm{m}$ & \\
\hline \multirow{4}{*}{ rs10244329 (A/T) } & Anti-CCP & Positive & $270(55.44)$ & $186(38.19)$ & $31(6.37)$ & 0.583 & $726(74.54)$ & $248(25.46)$ & 0.314 \\
\hline & \multirow{3}{*}{$\mathrm{RF}$} & Negative & $45(60.81)$ & $26(35.14)$ & $3(4.05)$ & & $116(78.38)$ & $32(21.62)$ & \\
\hline & & Positive & $262(54.60)$ & $187(39.04)$ & $30(6.26)$ & 0.319 & $711(74.22)$ & $247(25.78)$ & 0.129 \\
\hline & & Negative & $61(62.89)$ & $32(32.99)$ & $4(4.12)$ & & $154(79.38)$ & $40(20.62)$ & \\
\hline \multirow{4}{*}{ rs2071045 (C/T) } & \multirow[t]{2}{*}{ Anti-CCP } & Positive & $159(32.65)$ & $232(47.64)$ & $96(19.71)$ & 0.215 & $550(56.47)$ & $424(43.53)$ & 0.825 \\
\hline & & Negative & $21(28.38)$ & $43(58.11)$ & $10(13.51)$ & & $85(57.43)$ & $63(42.57)$ & \\
\hline & \multirow[t]{2}{*}{$\mathrm{RF}$} & Positive & $153(31.94)$ & $232(48.43)$ & $94(19.63)$ & 0.607 & $538(56.16)$ & $420(43.84)$ & 0.351 \\
\hline & & Negative & $34(35.05)$ & $48(49.48)$ & $15(15.46)$ & & $116(59.79)$ & $78(40.21)$ & \\
\hline \multirow{4}{*}{ rs2167270 (G/A) } & \multirow[t]{2}{*}{ Anti-CCP } & Positive & $294(60.37)$ & $173(35.52)$ & $20(4.11)$ & 0.973 & $761(78.13)$ & $213(21.87)$ & 0.234 \\
\hline & & Negative & $52(70.27)$ & $18(24.32)$ & $4(5.41)$ & & $122(82.43)$ & $26(17.57)$ & \\
\hline & \multirow[t]{2}{*}{$\mathrm{RF}$} & Positive & $290(60.54)$ & $168(35.07)$ & $21(4.39)$ & 0.373 & 748 (78.08) & $210(21.92)$ & 0.179 \\
\hline & & Negative & $66(68.04)$ & $28(28.87)$ & $3(3.09)$ & & $160(82.47)$ & $34(17.53)$ & \\
\hline
\end{tabular}

M: major alleles; m: minor alleles; $n$ : number; SNP: single nucleotide polymorphism.

TABLE 4: Haplotype analysis of SNPs in leptin gene in RA patients and controls.

\begin{tabular}{|c|c|c|c|c|c|}
\hline Haplotype & Case $[n(\%)]$ & Control $[n(\%)]$ & $\chi^{2}$ & $P$ value & OR $(95 \% \mathrm{CI})$ \\
\hline \multicolumn{6}{|c|}{ rs2167270-rs10244329-rs2071045 } \\
\hline AAC & $2.41(0.002)$ & $1.50(0.001)$ & - & - & - \\
\hline AAT & $1.77(0.001)$ & $0.59(0.000)$ & - & - & - \\
\hline ATC & $5.19(0.004)$ & $7.48(0.006)$ & - & - & - \\
\hline ATT & $243.63(0.205)$ & $248.44(0.207)$ & 0.030 & 0.862 & $0.983(0.806-1.198)$ \\
\hline GAC & $666.07(0.560)$ & $671.51(0.561)$ & 0.005 & 0.944 & $0.994(0.845-1.170)$ \\
\hline GAT & $221.75(0.186)$ & $219.41(0.183)$ & 0.036 & 0.850 & $1.020(0.829-1.255)$ \\
\hline GTC & $3.33(0.003)$ & $4.52(0.004)$ & - & - & - \\
\hline GTT & $45.85(0.039)$ & $44.56(0.037)$ & 0.028 & 0.868 & $1.036(0.681-1.578)$ \\
\hline
\end{tabular}

CI: confidence interval; OR: odds ratios; $n$ : number.

TABLE 5: Characteristics of subjects included in plasma leptin level analysis.

\begin{tabular}{|c|c|c|c|}
\hline Characteristics & $\begin{array}{l}\text { RA patients } \\
(N=103)\end{array}$ & $\begin{array}{l}\text { Healthy } \\
\text { controls } \\
(N=95)\end{array}$ & $P$ value \\
\hline Age (years) mean $\pm S D$ & $52.68 \pm 11.98$ & $51.08 \pm 9.27$ & 0.305 \\
\hline Sex (female/male) & $90 / 13$ & $80 / 15$ & 0.523 \\
\hline Anti-CCP positive no. (\%) & $28(84.8)$ & - & - \\
\hline RF positive no. (\%) & $49(84.5)$ & - & - \\
\hline $\begin{array}{l}\text { Leptin levels }(\mathrm{ng} / \mathrm{ml}) \\
\text { mean } \pm \mathrm{SD}\end{array}$ & $10.90 \pm 7.80$ & $12.36 \pm 6.98$ & 0.17 \\
\hline
\end{tabular}

between RA patients $(10.90 \pm 7.80 \mathrm{ng} / \mathrm{ml})$ and healthy controls $(12.36 \pm 6.98 \mathrm{ng} / \mathrm{ml})(P>0.05)$ (Table 5). Further, in subgroup analyses, results showed no difference in plasma leptin levels between anti-CCP-/RF-positive and anti-CCP/RF-negative groups of RA patients (Table 6).

\section{Discussion}

Rheumatoid arthritis is a chronic, complex autoimmune disease characterized by thickening and hyperplasia of the
TABLE 6: Associations of plasma leptin levels and clinical features of RA patients.

\begin{tabular}{lccc}
\hline Clinical features & Group & $\begin{array}{c}\text { Leptin levels (ng/ml) } \\
\text { mean } \pm \text { SD }\end{array}$ & $P$ value \\
\hline \multirow{2}{*}{ Anti-CCP } & Positive & $10.43 \pm 7.74$ & 0.745 \\
& Negative & $9.19 \pm 8.08$ & \\
\multirow{2}{*}{ RF } & Positive & $11.12 \pm 8.03$ & 0.284 \\
& Negative & $7.99 \pm 7.51$ & \\
\hline
\end{tabular}

synovial line alongside permanent inflammation, causing severe disability and early death [3]. Although the exact pathogenesis of RA remains obscure, it may be associated with $\mathrm{T}$ cell immune responses and $\mathrm{B}$ cell-induced antibodies. In addition, cytokines from various immune cells play important roles in the pathogenesis of RA [20]. Increasing studies have confirmed that leptin plays important roles in inflammation and autoimmunity including RA [13-19]. Numerous studies have found significantly elevated serum levels of leptin in RA patients [27-35]. Nevertheless, results from these studies were inconsistent, and several studies had suggested decreased serum levels of leptin in RA patients [38-41]. Although the relationship is complex, emerging 
evidence has pointed out that leptin has been implicated in RA [7, 9, 20-26].

The role of leptin gene in autoimmune diseases has received much attention in recent years [42-46]. Farrokhi et al. discovered a notable difference in allele/genotype frequencies of the leptin gene among MS patients and health controls suggesting that leptin plays a crucial role in the susceptibility to MS and its severity [42]. Yousefian et al. also revealed that leptin polymorphisms were related to the risk of MS and its clinical symptoms [43]. Most recently, Chen et al. established a transgenic leptin pig overexpressing leptin and observed manifestations of SLE in this transgenic pig strain [44]. But a previous study of our group has not discovered the association between leptin polymorphisms with SLE in a Chinese population [45], which is consistent with previous studies [46].

It also has been reported that leptin-deficient mice had decreased levels of TNF- $\alpha$ and IL- $1 \beta$, a less severe arthritis induced by antigen and defective cell-mediated immunity [47], whereas the reduction of leptin levels owing to fasting can lead to an improvement of clinical symptoms in RA patients [52]. Garcia-Bermudez et al. have assessed the relationships between leptin rs2167270 (19 G>A) gene polymorphism and the susceptibility to RA and have not found the association between leptin rs2167270 polymorphism and susceptibility to RA [48]. Afterward, Ali et al. have evaluated the association of leptin gene D7S1875 polymorphism with the risk for developing RA and severity of joint damage in patients with RA. The study concluded that the short allele of the D7S1875 (leptin gene) marker increases the risk for developing RA, but no association was observed between its allele/genotypes and RA [49].

Above all, we supposed that leptin gene polymorphism plays a critical role in the pathogenesis of RA. However, in this study, we did not discover any significant relationships between leptin gene polymorphism and RA. The three SNP polymorphisms did not achieve a significant difference in either genotype distributions or allele frequencies between RA patients and controls. In addition, no significant difference in haplotype distributions of these three SNP polymorphisms between RA patients and healthy controls was observed. Moreover, there was no significant difference of the three SNP polymorphisms under two main genetic models (dominant and recessive models) between RA patients and controls. Furthermore, no difference was detected in plasma leptin concentrations between RA patients and controls, and no association was shown between plasma leptin levels with clinical features of RA patients.

Finally, leptin rs10244329, rs2071045, and rs2167270 polymorphisms were shown to not be associated with susceptibility to RA. However, since this is not an overall study, the possible role of leptin in RA cannot be completely excluded. Some of the limitations in our study may affect the accuracy of the results, such as ethnic background, sample size, BMI, and patients with different disease activities, duration, and treatment. In addition, we cannot rule out that other polymorphisms in the leptin gene may be associated with RA. Therefore, it is also necessary to conduct repeated studies with larger sample sizes in different populations in the future.

\section{Data Availability}

The data are available upon request.

\section{Conflicts of Interest}

The authors declare that there is no conflict of interest regarding the publication of this paper.

\section{Acknowledgments}

This work was supported by grants from the National Natural Science Foundation of China (81573222) and the Natural Science Foundation of Anhui Higher Education Institutions of China (KJ2019A0230).

\section{References}

[1] Y. H. Lee, P. H. Lew, C. W. Cheah, M. T. Rahman, N. A. Baharuddin, and R. D. Vaithilingam, "Potential mechanisms linking periodontitis to rheumatoid arthritis," Journal of the International Academy of Periodontology, vol. 21, no. 3, pp. 99-110, 2019.

[2] Y. Ma, X. Zhang, D. Fan, Q. Xia, M. Wang, and F. Pan, "Common trace metals in rheumatoid arthritis: a systematic review and meta-analysis," Journal of Trace Elements in Medicine and Biology, vol. 56, pp. 81-89, 2019.

[3] J. S. Smolen, D. Aletaha, A. Barton et al., "Rheumatoid arthritis," Nature Reviews Disease Primers, vol. 4, no. 1, article 18001, 2018.

[4] I. Rudan, S. Sidhu, A. Papana et al., "Prevalence of rheumatoid arthritis in low- and middle-income countries: a systematic review and analysis," Journal of Global Health, vol. 5, article 010409, 2015.

[5] D. van der Woude and A. H. M. van der Helm-van Mil, "Update on the epidemiology, risk factors, and disease outcomes of rheumatoid arthritis," Best Practice \& Research. Clinical Rheumatology, vol. 32, no. 2, pp. 174-187, 2018.

[6] A. M. Bourne, R. V. Johnston, S. Cyril et al., "Scoping review of priority setting of research topics for musculoskeletal conditions," BMJ Open, vol. 8, no. 12, article e023962, 2018.

[7] M. Carrión, K. W. Frommer, S. Pérez-García, U. MüllerLadner, R. P. Gomariz, and E. Neumann, "The adipokine network in rheumatic joint diseases," International Journal of Molecular Sciences, vol. 20, no. 17, p. 4091, 2019.

[8] P. Ruscitti, P. di Benedetto, O. Berardicurti et al., "Adipocytokines in rheumatoid arthritis: the hidden link between inflammation and cardiometabolic comorbidities," Journal of Immunology Research, vol. 2018, Article ID 8410182, 10 pages, 2018.

[9] M. F. B. de Resende Guimarães, M. V. M. de Andrade, C. J. Machado et al., "Leptin as an obesity marker in rheumatoid arthritis," Rheumatology International, vol. 38, no. 9, pp. 1671-1677, 2018.

[10] J. A. de Jesús Batún-Garrido, M. Salas-Magaña, I. E. JuárezRojop, E. Hernández-Núñez, and F. Olán, "Relationship between leptin concentrations and disease activity in patients with rheumatoid arthritis," Medicina Clínica (Barcelona), vol. 150, no. 9, pp. 341-344, 2018.

[11] Y. H. Lee and S. C. Bae, "Circulating leptin level in rheumatoid arthritis and its correlation with disease activity: a meta- 
analysis," Zeitschrift für Rheumatologie, vol. 75, no. 10, pp. 1021-1027, 2016.

[12] Y. Zhang, R. Proenca, M. Maffei, M. Barone, L. Leopold, and J. M. Friedman, "Positional cloning of the mouse obese gene and its human homologue," Nature, vol. 372, no. 6505, pp. 425-432, 1994.

[13] V. Francisco, J. Pino, V. Campos-Cabaleiro et al., "Obesity, fat mass and immune system: role for leptin," Frontiers in Physiology, vol. 9, p. 640, 2018.

[14] V. Francisco, C. Ruiz-Fernandez, J. Pino et al., “Adipokines: linking metabolic syndrome, the immune system, and arthritic diseases," Biochemical Pharmacology, vol. 165, pp. 196-206, 2019.

[15] H. Han and W. Zhou, "Leptin and its Derivatives: a potential target for autoimmune diseases," Curr Drug Targets, vol. 20, no. 15, pp. 1563-1571, 2019.

[16] R. Maurya, P. Bhattacharya, R. Dey, and H. L. Nakhasi, "Leptin functions in infectious diseases," Frontiers in Immunology, vol. 9, p. 2741, 2018.

[17] A. Perez-Perez, T. Vilarino-Garcia, P. Fernandez-Riejos, J. Martin-Gonzalez, J. J. Segura-Egea, and V. Sanchez-Margalet, "Role of leptin as a link between metabolism and the immune system," Cytokine \& Growth Factor Reviews, vol. 35, pp. 71-84, 2017.

[18] V. Abella, M. Scotece, J. Conde et al., "Leptin in the interplay of inflammation, metabolism and immune system disorders," Nature Reviews Rheumatology, vol. 13, no. 2, pp. 100-109, 2017.

[19] A. La Cava, "Leptin in inflammation and autoimmunity," Cytokine, vol. 98, pp. 51-58, 2017.

[20] G. Tian, J. N. Liang, Z. Y. Wang, and D. Zhou, "Emerging role of leptin in rheumatoid arthritis," Clinical and Experimental Immunology, vol. 177, no. 3, pp. 557-570, 2014.

[21] M. Bokarewa, D. Bokarew, O. Hultgren, and A. Tarkowski, "Leptin consumption in the inflamed joints of patients with rheumatoid arthritis," Annals of the Rheumatic Diseases, vol. 62, no. 10, pp. 952-956, 2003.

[22] C. Y. Chen, C. Y. Tsai, P. C. Lee, and S. D. Lee, "Long-term etanercept therapy favors weight gain and ameliorates cachexia in rheumatoid arthritis patients: roles of gut hormones and leptin," Current Pharmaceutical Design, vol. 19, no. 10, pp. 1956-1964, 2013.

[23] S. Manavathongchai, A. Bian, Y. H. Rho et al., "Inflammation and hypertension in rheumatoid arthritis," The Journal of Rheumatology, vol. 40, no. 11, pp. 1806-1811, 2013.

[24] A. S. Elwakkad, R. N. Said, S. I. Muhammad, M. T. Saleh, and A. Elhamshary, "Role for leptin and prolactin in human juvenile rheumatic diseases," Pakistan Journal of Biological Sciences, vol. 10, no. 12, pp. 1984-1989, 2007.

[25] L. Navarini, D. P. E. Margiotta, M. Vadacca, and A. Afeltra, "Leptin in autoimmune mechanisms of systemic rheumatic diseases," Cancer Letters, vol. 423, pp. 139-146, 2018.

[26] E. Toussirot, F. Michel, D. Binda, and G. Dumoulin, "The role of leptin in the pathophysiology of rheumatoid arthritis," Life Sciences, vol. 140, pp. 29-36, 2015.

[27] B. Roth, J. Manjer, and B. Ohlsson, "Microscopic colitis is associated with several concomitant diseases," Drug Target Insights, vol. 7, pp. 19-25, 2013.

[28] Y. Sugioka, M. Tada, T. Okano, H. Nakamura, and T. Koike, "Acquired leptin resistance by high-fat feeding reduces inflammation from collagen antibody-induced arthritis in mice,"
Clinical and Experimental Rheumatology, vol. 30, no. 5, pp. 707-713, 2012.

[29] S. Muraoka, N. Kusunoki, H. Takahashi, K. Tsuchiya, and S. Kawai, "Leptin stimulates interleukin-6 production via Janus kinase 2/signal transducer and activator of transcription 3 in rheumatoid synovial fibroblasts," Clinical and Experimental Rheumatology, vol. 31, no. 4, pp. 589-595, 2013.

[30] T. Yoshino, N. Kusunoki, N. Tanaka et al., "Elevated serum levels of resistin, leptin, and adiponectin are associated with C-reactive protein and also other clinical conditions in rheumatoid arthritis," Internal Medicine, vol. 50, no. 4, pp. 269275, 2011.

[31] M. Mohammad-Shahi, F. Haidari, B. Rashidi, A. A. Saei, S. Mahboob, and M. R. Rashidi, "Comparison of the effects of genistein and daidzein with dexamethasone and soy protein on rheumatoid arthritis in rats," BioImpacts: BI, vol. 1, no. 3, pp. 161-170, 2011.

[32] D. Xibille-Friedmann, C. Bustos-Bahena, S. Hernandez-Gongora, R. Burgos-Vargas, and J. L. Montiel-Hernandez, "Twoyear follow-up of plasma leptin and other cytokines in patients with rheumatoid arthritis," Annals of the Rheumatic Diseases, vol. 69, no. 5, pp. 930-931, 2010.

[33] Y. H. Rho, J. Solus, T. Sokka et al., “Adipocytokines are associated with radiographic joint damage in rheumatoid arthritis," Arthritis and Rheumatism, vol. 60, no. 7, pp. 19061914, 2009.

[34] M. Otero, R. Lago, R. Gomez et al., "Changes in plasma levels of fat-derived hormones adiponectin, leptin, resistin and visfatin in patients with rheumatoid arthritis," Annals of the Rheumatic Diseases, vol. 65, no. 9, pp. 1198-1201, 2006.

[35] S. M. Olama, M. K. Senna, and M. Elarman, "Synovial/serum leptin ratio in rheumatoid arthritis: the association with activity and erosion," Rheumatology International, vol. 32, no. 3, pp. 683-690, 2012.

[36] M. Taghadosi, Z. Samimi, S. Assar, M. R. Salahshoor, and C. Jalili, "Plasma leptin does not reflect the effect of high body mass index on disease activity in rheumatoid arthritis," Immunological Investigations, vol. 49, no. 1-2, pp. 32-45, 2020.

[37] A. Dervisevic, H. Resic, S. Sokolovic et al., "Leptin is associated with disease activity but not with anthropometric indices in rheumatoid arthritis patients," Archives of Medical Science, vol. 14, no. 5, pp. 1080-1086, 2018.

[38] H. Hayashi, K. Satoi, N. Sato-Mito et al., "Nutritional status in relation to adipokines and oxidative stress is associated with disease activity in patients with rheumatoid arthritis," Nutrition, vol. 28, no. 11-12, pp. 1109-1114, 2012.

[39] K. Hamaguchi, A. Itabashi, Y. Kuroe et al., "Analysis of adipose tissues and stromal vascular cells in a murine arthritis model," Metabolism, vol. 61, no. 12, pp. 1687-1695, 2012.

[40] A. I. Martin, E. Castillero, M. Granado, M. Lopez-Menduina, M. A. Villanua, and A. Lopez-Calderon, "Adipose tissue loss in adjuvant arthritis is associated with a decrease in lipogenesis, but not with an increase in lipolysis," The Journal of Endocrinology, vol. 197, no. 1, pp. 111-119, 2008.

[41] M. D. Hayward, B. K. Jones, A. Saparov et al., "An extensive phenotypic characterization of the hTNF $\alpha$ transgenic mice," BMC Physiology, vol. 7, no. 1, p. 13, 2007.

[42] M. Farrokhi, M. Dabirzadeh, E. Fadaee et al., "Polymorphism in leptin and leptin receptor genes may modify leptin levels and represent risk factors for multiple sclerosis," Immunological Investigations, vol. 45, no. 4, pp. 328-335, 2016. 
[43] M. Yousefian, R. Nemati, G. Daryabor et al., "Gender-specific association of leptin and adiponectin genes with multiple sclerosis," The American Journal of the Medical Sciences, vol. 356, no. 2, pp. 159-167, 2018.

[44] J. Chen, W. Zeng, W. Pan et al., "Symptoms of systemic lupus erythematosus are diagnosed in leptin transgenic pigs," PLoS Biology, vol. 16, no. 8, article e2005354, 2018.

[45] H. M. Li, T. P. Zhang, R. X. Leng et al., "Association of leptin and leptin receptor gene polymorphisms with systemic lupus erythematosus in a Chinese population," Journal of Cellular and Molecular Medicine, vol. 21, no. 9, pp. 1732-1741, 2017.

[46] J. Zhao, H. Wu, C. D. Langefeld et al., "Genetic associations of leptin-related polymorphisms with systemic lupus erythematosus," Clinical Immunology, vol. 161, no. 2, pp. 157-162, 2015.

[47] N. Busso, A. So, V. Chobaz-Peclat et al., "Leptin signaling deficiency impairs humoral and cellular immune responses and attenuates experimental arthritis," Journal of Immunology, vol. 168, no. 2, pp. 875-882, 2002.

[48] M. Garcia-Bermudez, C. Gonzalez-Juanatey, L. RodriguezRodriguez et al., "Lack of association between LEP rs2167270 (19 G>A) polymorphism and disease susceptibility and cardiovascular disease in patients with rheumatoid arthritis," Clinical and Experimental Rheumatology, vol. 29, no. 2, pp. 293-298, 2011.

[49] G. L. Ali, S. Kapur, S. Chinmayi et al., "A study of genetic markers in patients of rheumatoid arthritis and their corelation with severity of the disease," The Journal of the Association of Physicians of India, vol. 65, no. 9, pp. 32-36, 2017.

[50] D. Aletaha, T. Neogi, A. J. Silman et al., "2010 rheumatoid arthritis classification criteria: an American College of Rheumatology/European League Against Rheumatism collaborative initiative," Arthritis \& Rheumatology, vol. 62, no. 9, pp. 2569-2581, 2010.

[51] Z. Li, Z. Zhang, Z. He et al., "A partition-ligation-combination-subdivision EM algorithm for haplotype inference with multiallelic markers: update of the SHEsis (http://analysis.bio-x.cn)," Cell Research, vol. 19, no. 4, pp. 519-523, 2009.

[52] D. A. Fraser, J. Thoen, J. E. Reseland, O. Forre, and J. KjeldsenKragh, "Decreased CD4+ lymphocyte activation and increased interleukin-4 production in peripheral blood of rheumatoid arthritis patients after acute starvation," Clinical Rheumatology, vol. 18, no. 5, pp. 394-401, 1999. 